\title{
Verbal processes in academic language in Spanish: exploring discourse genres within the systemic functional framework
}

Natalia Ignatieva $^{* \dagger}$ and Daniel Rodríguez-Vergara ${ }^{+}$

\author{
* Correspondence: ignatiev@unam.mx \\ †Equal contributors \\ Foreign Language Center, National \\ Autonomous University of Mexico, \\ Mexico City, Mexico
}

\begin{abstract}
This work is part of the research project "Verbal processes in academic writing in the light of Systemic Functional Grammar" which was developed at the Foreign Language Centre of the National Autonomous University of Mexico. The objective of the project is to analyze verbal transitivity in student writing and research articles from the Systemic Functional Linguistics perspective. Verbal transitivity analyzes locutional and symbolic processing constructions, and the participants involved in these constructions. Our goal in this paper is to present a study of student texts belonging to three genres of the university curriculum (question-answer, essay and review) and of expert texts (research articles) in terms of the verbal process frequency in each genre and each area. Besides, we are going to explore projecting characteristics of our corpus in general, and of the ten most frequent verbs in this corpus, in particular. The results indicate that there is an important variation among the verbal process frequencies and their projecting characteristics in different genres and areas under analysis.
\end{abstract}

Keywords: Verbal processes; Academic language; Genres

\section{Springer}

\section{Background}

In this paper we are going to present a systemic functional analysis focused on verbal processes that appear in student academic texts and research articles. This work forms part of the research project developed at the National Autonomous University of Mexico ${ }^{\mathrm{a}}$ (UNAM) which, in turn, is part of a major project, Systemics Across Languages (SAL) in its Latin American version ${ }^{\mathrm{b}}$. The results of this project were presented in several ISFC (International Systemic Functional Congress) and ALSFAL (Latin American Association of Systemic Functional Linguistics) congresses (Ignatieva 2011; Ignatieva and Zamudio 2012). Student texts were taken from our previous project which investigated the language of the humanities in Mexico and the United States (Ignatieva and Colombi 2014); one of its purposes was to collect student texts from humanistic areas which form part of the Corpus of Academic Language in Spanish (CLAE 2009). Thus, for the present analysis, we have taken CLAE texts belonging to three different genres: question-answers, essays, and reviews, written by Mexican students studying Spanish Literature. In addition, we formed another corpus with research articles taken from Mexican scientific journals, all of which deal with the area of Linguistics.

(c) 2015 Ignatieva and Rodríguez-Vergara; licensee Springer. This is an Open Access article distributed under the terms of the Creative Commons Attribution License (http://creativecommons.org/licenses/by/4.0), which permits unrestricted use, distribution, and reproduction in any medium, provided the original work is properly credited. 
First, we shall define the group of verbal processes found in these texts and determine their frequency in relation to the number of finite clauses in our corpora. Then we analyze the ten most frequent verbs of our corpora and their projecting characteristics. Finally we shall compare verbal process features discovered in different genres and areas. We shall begin with the theoretical perspective on which our project is based.

\section{The systemic functional model and transitivity}

The overall project as well as the present analysis are based on Systemic Functional Linguistics (SFL) originated by Halliday $(1978,1985 / 1994)$ and developed later by other researchers within this area (Martin 1985, 1992; Matthiessen 1995; Martin and Rose 2003; Thompson 1996/2004; Ghio and Fernández 2005; Montemayor-Borsinger 2009 , etc.). One of the principal ideas of this theory is to consider language as a system of subsystems based on their functions derived from the use of the language in its social context.

According to Halliday (1985/1994), language is structured to fulfill three main functions which he calls metafunctions; these are ideational, interpersonal and textual functions. The ideational one organizes our experience in the exterior and interior world, the interpersonal serves to express our interaction with others, and the textual metafunction to contextualize linguistic units and organize them as discourse.

The systemic theory is oriented towards language as a social process connected to a certain society and its culture; SFL puts emphasis on the social function of language, i.e. its use in a community in different social contexts (Halliday 1978). Among these social contexts, a context of culture and a context of situation are singled out. The latter is considered a dynamic organic configuration of three components named "field", "tenor" and "mode", that is, the nature of a social activity, the relations between the interlocutors, and the status assigned to language (what happens, who participates, and how the discourse is organized). The three components of the social context are construed in the discourse as ideational, interpersonal and textual meanings, respectively.

On the other hand, within these contextual components (field, tenor and mode) there is a systemic variation in the relative prominence of different options, which causes a functional variation in the language, i.e. register. Register is associated to the context of situation; it is a "variation according to usage" (Halliday and Hasan 1989); for example, an academic register is linked to an educational situation, in this case, a university context.

The concept of genre, on the contrary, is connected to the context of culture, emphasizing the idea that texts are used for some social purpose (Eggins and Martin 1997: 236). According to Colombi (2003: 80), "a genre can be seen as a frame or structure that gives meaning to different types of interactions, i.e. a genre is adapted to the social contexts in which it is used". In addition, a genre deploys the resources of a register in specific patterns in order to fulfill certain communicative goals (cf. Thompson 1996/ 2004: 43). In the case of a university sphere, an academic register can include such genres as essay, review, report, project, monograph, etc.

It can be concluded that both register and genre are construed by combining the three types of meanings, viz. ideational, interpersonal and textual, which are realized 
simultaneously in language-their distinct combinations produce an infinite variety of texts ${ }^{\mathrm{c}}$.

The three metafunctions mentioned above (ideational, interpersonal and textual) correspond to three systems on the lexicogrammatical level, i.e. TRANSITIVITY, MOOD and THEME, and in this way the system of TRANSITIVITY is the realization of the ideational metafunction, while the system of MOOD reflects the interpersonal metafunction, and the system of THEME represents the metatextual function (see Figure 1).

Thus, in terms of meaning potential, "transitivity is the ideational component in the meaning of the clauses" (Halliday 1968: 21). Transitivity is defined as the system that concerns different combinations of participants organized around a process in the clause. It refers to "a way of representing patterns of experience [...] of imposing order on the endless variation and flow of events" (Halliday 1985/1994: 106). In other words, it is the organization of the sentence to express experiential meanings.

Consequently, the transitivity system construes the world of experience into a set of process types. We would like to point out that Halliday first divided processes into three types, "material", "mental" and "relational" (Halliday 1968), and then he added three more types, "verbal", "behavioral" and "existential" (Halliday 1985/ 1994), but he considered the original three as the main types while the second group of three was thought of as "borderline" cases. Thus, the category of "verbal" processes is situated on the borderline between "mental" and "relational" processes because a symbolic relationship is construed in human consciousness and enacted in the form of language as saying, according to Halliday and Matthiessen (2004: 171). Matthiessen (1995) however, extended the main types to four (material, mental, relational and verbal) and in this way he included verbal processes in the above group arguing that verbal processes have their own characteristic traits that set them apart from the other process types. We shall follow Matthiessen's point of view.

Each process type provides its own model or schema for construing a particular domain of experience (Halliday and Matthiessen 2004: 170). This schema concerns the roles of the participants of the clauses in regard to a particular type of process. For example, material processes usually imply the existence of an Actor as the first participant and a Goal as the second participant (e.g. John hit the dog). Verbal processes have their own schema for construing the clause (Lavid, Arús and ZamoranoMansilla Lavid et al. 2010: 135-7) and now we shall comment on this schema.

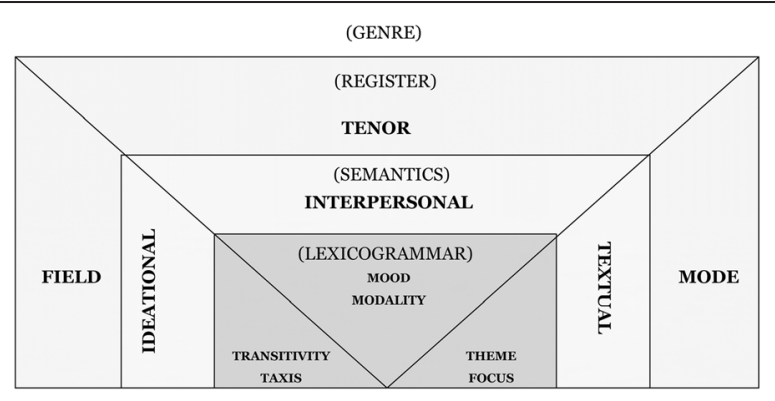

Figure 1 Stratal relationship between lexicogrammar, semantics, register and genre. 


\section{Participants and projection in verbal clauses}

According to Halliday and Matthiessen (2004), the most common participants in a verbal clause are Sayer, Receiver and Verbiage. For example, in (1), Sancho is the Sayer, le ('him') is the Receiver and lo contrario ('the opposite') is the Verbiage.

(1) Sancho le dice lo contrario... (Q-A, 13)

(Sancho tells him the opposite...)

Only the Sayer is considered by Halliday a "direct" or obligatory participant and the only one really necessary, while the other two are thought to be "oblique" or non-obligatory.

Apart from the participants, the other way to transmit what is said is to present the message with the help of what is called in traditional grammar "direct or indirect speech." In (2) we deal with two clauses that form a clause complex, and only the primary clause is verbal; the next is a reported clause, the relation between the two being hypotactic. In (3) there is also a clause complex, but this time with a paratactic relation; besides, the second clause is now a quoted one:

(2) Don Quijote afirma que está consciente. (Q-A, 7)

(Don Quijote affirms that he is conscious.)

(3) El caballero le responde lo siguiente: "eso no puede ser menos en ninguna manera." (E, 2)

(The gentleman answers him as follows: "that could not be less in any way.")

The content of the message is called a "locution" (direct or indirect), but this locution is not analyzed as a participant in the verbal process because it is found outside the verbal clause (see Figure 2). So, the difference between a Verbiage and a locution is that whereas the former is construed by a noun group, the latter is construed by a clause. The logico-semantic relation between a primary and a secondary member of a clause nexus (when the message is expressed through reported speech) is called "projection" in SFL (Halliday and Matthiessen 2004: 376). This relationship between the two members is like the one "between a picture (projected clause) and its frame (projecting clause); together they make up a single complex unit, but neither is actually part of the other" (Thompson 1996/2004: 103).

In accordance with the above mentioned, verbal processes are divided into two groups: projecting verbal processes and non-projecting ones. Projecting processes are those that can project (see (2-3)), i.e. they transmit what is said by means of direct or indirect locution, while verbal processes that cannot project take participants to express the content of the message (see (1)). However, some processes can act as either, projecting or non-projecting:

(4) ... la doncella le pide dinero a Don Quijote para Dulcinea. (Q-A, 2)

(...the maid asks Don Quijote for money for Dulcinea.)

(5) Le pide que corteje a Camila, cuya fidelidad desea poner a prueba. (E, 2)

(He asks him to court Camila, whose fidelity he wants to probe.) 


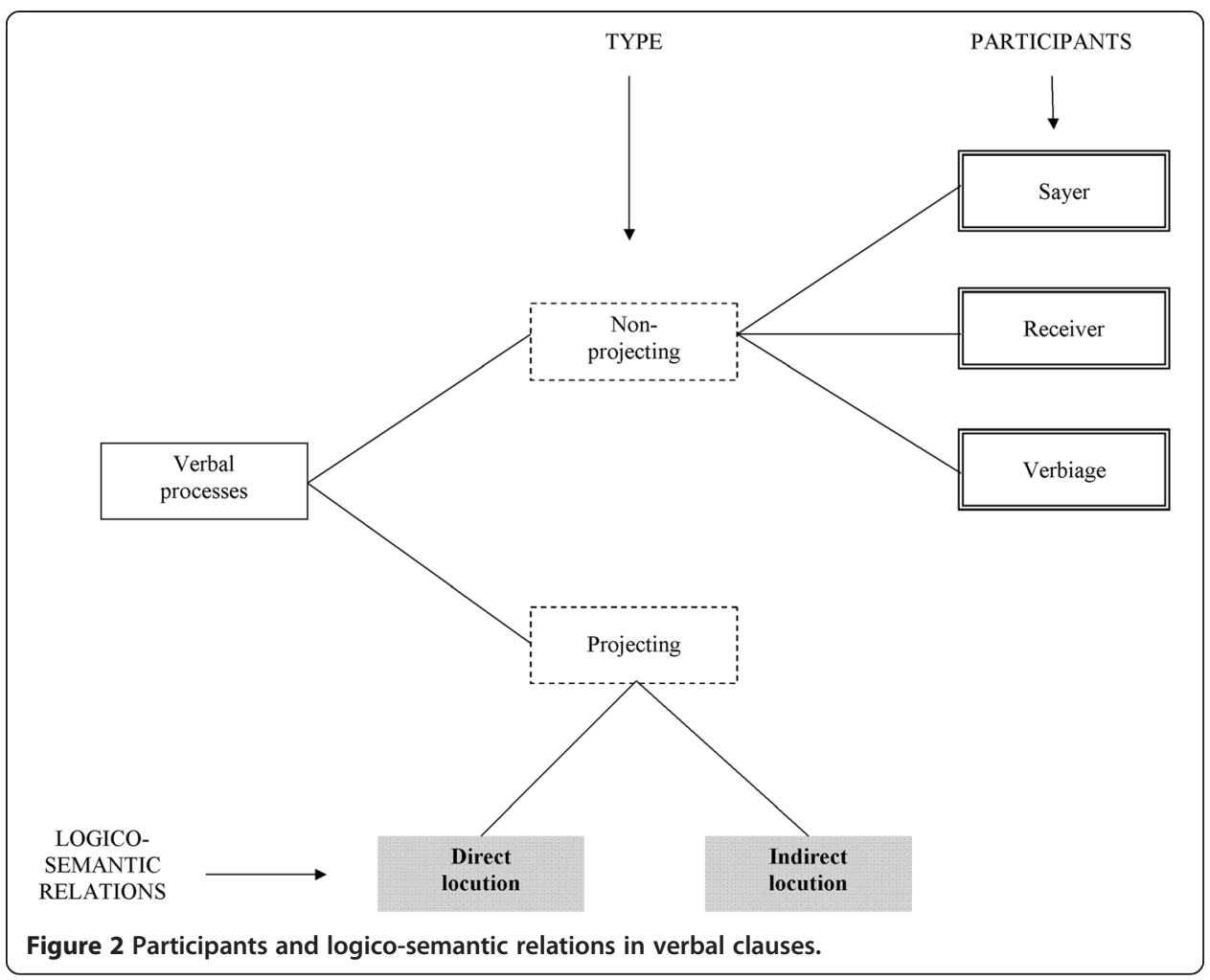

It is worth mentioning that not all linguists consider the latter as verbal (Martin et al. 1997) taking projection as the criterion for distinguishing between verbal processes (that project) and other communication processes (that do not project) and in this case are excluded from this group and defined as behavioural. In our project we adopt the "inclusive" point of view following Caffarel (2006) and Banks to appear as both types of processes participate in the act of communication.

\section{Methods}

As already mentioned, we utilized two corpora. The first was the CLAE corpus, which contains texts written by students from the Faculty of Philosophy and Arts at the UNAM. From this corpus, we analyzed 31 texts of three genres written by Literature students: question-answers, essays and reviews. The first genre was part of a written exam that contained questions answered by students during class time. The second is a longer text which was written by students outside the class as a term paper. The last one was also written outside the class.

On the other hand, the expert corpus was formed by research articles taken from five Mexican journals: Razón y Palabra, Revista de Humanidades, Escritos, Tópicos del Seminario, and Comunicación y Sociedad. All the articles are about discourse analysis and what motivated their selection was the fact that they contained the term 'discourse' in their title. As in the case of the student texts, all the articles are written by Mexican authors. Table 1 gives the number of texts used in each corpus ${ }^{\mathrm{d}}$.

In each of the texts, we identified and quantified all the verbal processes, as well as the involved participants and projected clauses. We also counted all the finite clauses 
Table 1 Number of texts in each corpus

\begin{tabular}{llllll}
\hline & Q-A & Essays & Reviews & Research articles & Total \\
\hline Student corpus & 15 & 7 & 9 & & 31 \\
Expert corpus & & & & 10 & 10 \\
\hline
\end{tabular}

(including ranking and embedded ones) in order to calculate the relative frequencies of verbal constructions, as opposed to absolute ones. The results of the study will be presented in two ways. First, we will present the quantitative part of the analysis by showing the proportion and frequency of the verbal processes. Second, we will explore the qualitative part of the analysis by comparing and contrasting the genres.

\section{Results}

\section{Quantitative analysis}

In this section the data concerning the percentage of verbal processes are presented (see Table 2); it was taken as the ratio between the number of verbal processes in a text and the number of finite clauses in that same text. First, we shall comment on the results in each of the student genres.

Table 2 shows that question-answers are relatively short texts since the average number of clauses per text is 28.4 . In this genre, $25.3 \%$ of all processes in finite clauses are verbal. The table also includes the standard deviation, which is the measure of the dispersion of the sample scores around the average score. In this case, the standard deviation is \pm 13 , which means that if we add or deduct this number to the total average (25.3), we get the maximum or minimum number of verbal processes that a text can

\section{Table 2 Percentages of verbal processes}

\begin{tabular}{lllll}
\hline & Question-answers & Essays & Reviews & Articles \\
\hline 1 & 26 & 13.88 & 34.4 & $>13.08$ \\
2 & 36 & $<19.99$ & 44 & $>13.87$ \\
3 & 36 & 14.28 & $<56.7$ & 18.54 \\
4 & 14 & $>5.19$ & $>16.9$ & 28.1 \\
5 & $<55.5$ & 10 & $>16.25$ & 29.17 \\
6 & 31 & 7.05 & 31.1 & 15.35 \\
7 & 23 & 9.41 & 21 & 26.19 \\
8 & $>11$ & & $<49.15$ & $>14.29$ \\
9 & 18 & & 28.5 & 23.94 \\
10 & 13 & & & $<38.87$ \\
11 & 26 & & & \\
12 & 27 & & & \\
13 & 22 & & & \\
14 & $>6.7$ & & & \\
15 & $>7$ & 11.3 & 33.09 & \\
Average number of verbal processes & 25.3 & 62.7 & \\
Average number of clauses & 28.4 & \pm 14.3 & \\
Standard deviation & \pm 13 & & & \\
\hline$<$ Above & & & & \\
\hline
\end{tabular}

$<$ Above standard deviation threshold

$>$ Below standard deviation threshold. 
have in order to be represented by the total average. In question-answers, one text is above that threshold (5) and three are below (8, 14 and 7). This means text 5 uses an atypical high number of verbal processes, and texts 8, 14 and 7 use an atypical low number of them.

It can also be seen in Table 2 that essays are longer than question-answers since their average number of clauses per text is 128 . However, in essays, only $11.3 \%$ of all processes are verbal. In this case, the standard deviation is \pm 5 , and by adding and deducting this number to the average, we get one text above the representation threshold (2) and one below (4).

As for reviews, they are longer than question-answers, but shorter than essays since they have an average number of 62.7 clauses per text. Table 2 shows that $33.09 \%$ of all the processes in reviews are verbal, which is higher than in question-answers and essays. Here, the standard deviation is \pm 14 .3, so there are two texts above this representation threshold (3 and 8 ) and two below (4 and 5).

Now we shall pass on to the expert corpus in order to examine the data of the verbal frequency in research articles.

Articles are far longer than any of the student genres since they have an average number of 351.2 clauses per text. In articles, $22.95 \%$ of the total number of processes are verbal. Here the standard deviation is \pm 8.5 , and, as can be observed, there is one text above the representation threshold and three below. Overall, we have found more texts below the representation threshold (9) than above (5).

\section{Contrastive analysis}

Now we are going to compare the student corpus and the expert corpus in terms of the percentage of verbal processes. Figure 3 shows the differences between the verbal process percentages in each of the student genres.

As can be observed, essays show the lowest frequency of verbal processes (11.30) followed by question-answers with a frequency that is more than double (25.30), and finally, reviews with the highest percentage (33.09), which is approximately three times more than essays. In addition, reviews were the student texts with the lowest standard deviation $( \pm 5)$. The frequent use of verbal processes in reviews might be due to the constant reference to other authors that give their opinion on the reviewed books. It is common that the student reviewer, in addition to giving his/her own opinion, compares it to others' critiques in order to arrive at a general balanced evaluation:

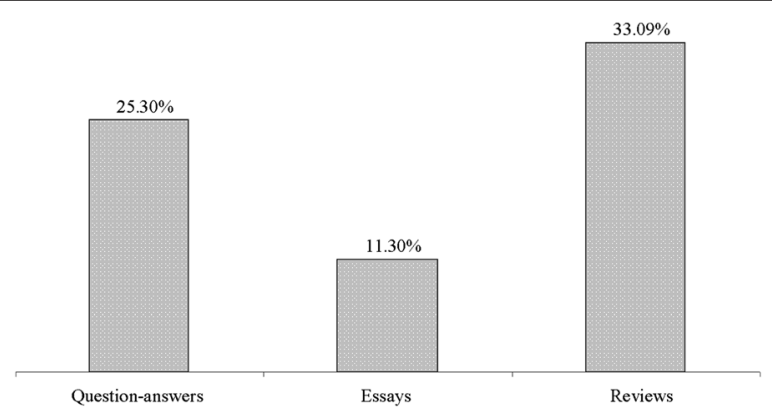

Figure 3 Percentages of verbal processes in the student genres. 
(6) El autor no defiende la comedia española; lo que ampara es el desenrede de esas obras falsas y complicadas y que se abran rutas nuevas en las comedias españolas para facilitar el disfrute del público en general. $(\mathrm{R}, 1)$

(The author does not defend the Spanish comedy; what he advocates is the untangling of those complex and false works and the opening up of new paths in Spanish comedies in order to facilitate the public's enjoyment in general.)

In essays in contrast, the students normally do not recur so much to authorities but rather limit themselves to express their own thoughts in the concluding section, although they seldom use verbal processes for that purpose; alternatively, they frequently use mental clauses such as I think and I believe:

(7) Creo que al igual que cada personaje que encontramos en el Quijote, el de Dulcinea también puede ser interpretado de distintas formas según el lector. (E, 2) (I think that, just as every character found in Don Quijote, Dulcinea can also be interpreted in several ways depending on the reader.)

Finally, a relatively large number of verbal processes in question-answers might be explained by the fact that students report some of the character dialogues from the book they read:

(8) Don Quijote enojado, dice que las comparaciones no son buenas. (P-R, 1)

(Don Quijote, angry, says that comparisons are not good.)

In Figure 4, we may compare the data of the student genres and the journal articles. For this purpose, the percentages of the three student genres were merged into one.

Figure 4 shows that once we merge the percentages of the student genres into one, the final percentage is similar to that found in journal articles. Thus, we can state a general similarity in the use of verbal processes by students and authors of journal articles. However, differences can also be found as to what types of verbal processes are used in each corpus.

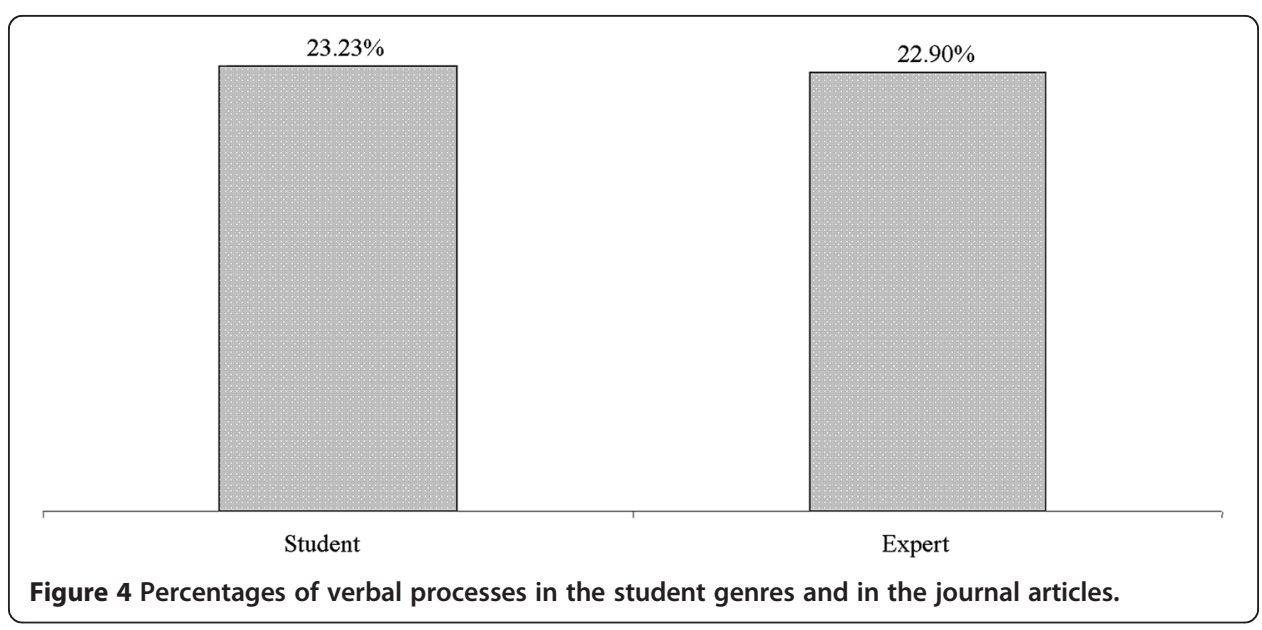


Our next step was to explore the ten most frequent verbs in both corpora. Figure 5 contains the data of the ten most frequent verbal processes in the student corpus, while Figure 6 presents the same data for the expert one.

When we compare the two figures, we see that whereas in the student corpus the most frequent verbal process (decir) has 42 more occurrences than the second (mencionar), in the expert corpus the most frequent verbal process (definir) has just 10 more occurrences than the second (hablar). So, while the process decir does most of the semiotic verbal labor in the student texts, in the articles the division of labor is more balanced amongst different verbal processes.

The most frequent verbal process in the student texts (decir) is in third place in the articles, but the most frequent verbal process in the articles (definir) does not even appear in the student text chart. The frequency of the process decir is high in the student writing perhaps because their repertoire is rather limited and they seldom use other processes to quote and report. In contrast, the authors of the articles show a bigger concern for defining concepts utilized in the discipline of discourse analysis, a field whose research topics tend to be abstract. That is why the process definir plays such an important role in this corpus. The following are sentences taken from two of the research articles that contain the process definir.

(9) La coyuntura politica ha sido definida como un desplazamiento significativo de la correlación de fuerzas. (A, 10)

(The political juncture has been defined as a significant displacement of the power correlation.)

(10) La argumentación puede ser definida como la presión simbólica que un individuo ejerce sobre una audiencia. (A, 4)

(Argumentation can be defined as the symbolic pressure that an individual exerts on anaudience.)

Finally, we present the projecting characteristics of the most frequent verbal processes. Figures 7 and 8 show these data in both corpora, respectively.

The figures show that whereas in the student writing all verbal processes project at least once, in the research articles only five of them are projecting. What is more, the two most frequent verbal processes in the expert corpus (definir and hablar) show no

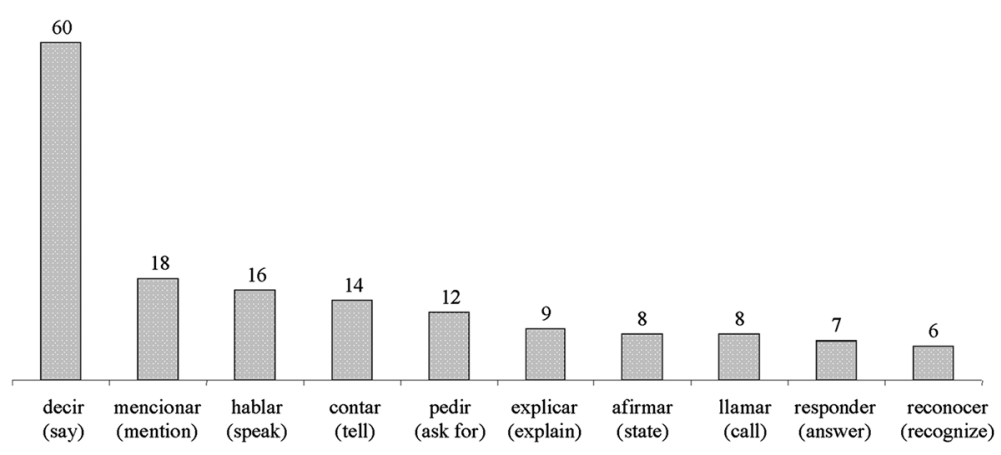

Figure $\mathbf{5}$ The ten most frequent verbal processes in the student corpus. 


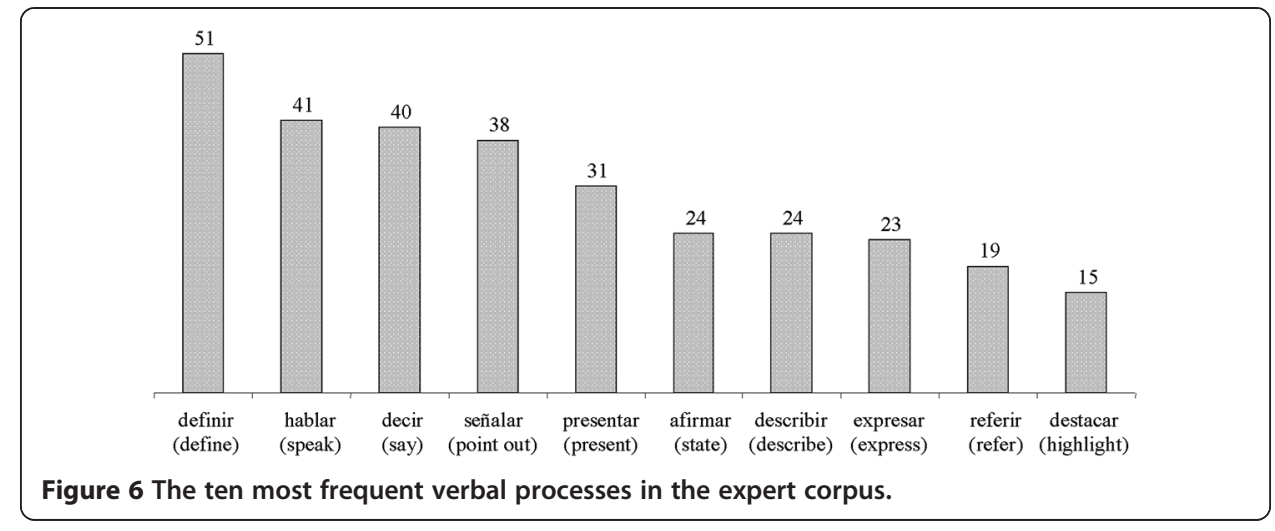

projection at all. The verbal process with most projections in both the student and the expert corpus is decir. However, in the student corpus the occurrences of decir with projection are more than double than those with no projection (41 vs. 19), but in the expert corpus the difference is of only 6 units (23 vs. 17). The following are sentences with the same process, but with different projecting characteristics.

(11) Señala Marta Lamas que "la sexualidad es una elaboración psíquica y cultural construida discursivamente". (A, 5)

(Marta Lamas points out that "sexuality is a psychic and cultural construal discursively produced.")

(12) Los servicios de espionaje norteamericano señalan a Osama Bin Laden como el autor intelectual de varios ataques en contra de Estados Unidos. (A, 10) (North-American espionage services point out Osama Bin Laden as the intellectual author of various attacks against the United States.)

In general, the student corpus has more projections than the expert one. This is perhaps because the students use a more colloquial style, and, as Halliday (1989) has pointed out, colloquial language is characterized for having a generally higher degree of grammatical intricacy than specialized language. As he asserts, grammatical intricacy has to do with the number of ranking clauses that have a tactic relationship with one another in a sentence. Projection is one kind of logico-semantic relationship that can

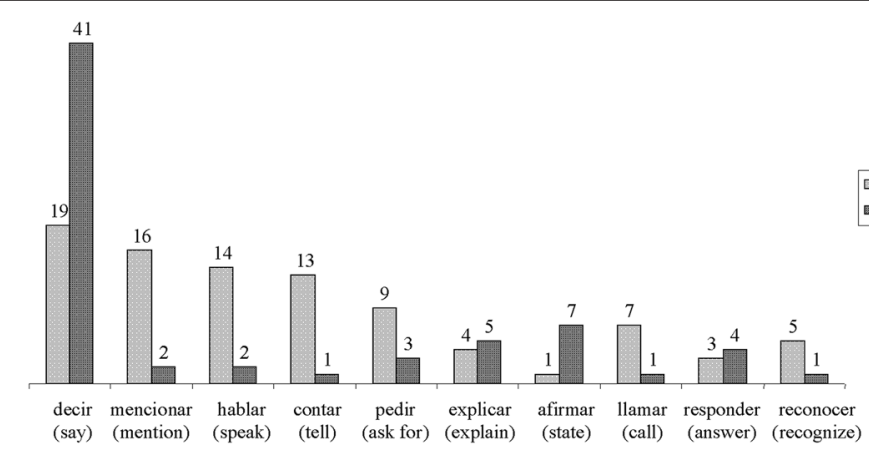

Figure 7 Projecting characteristics of the most frequent verbal processes in the student corpus. 


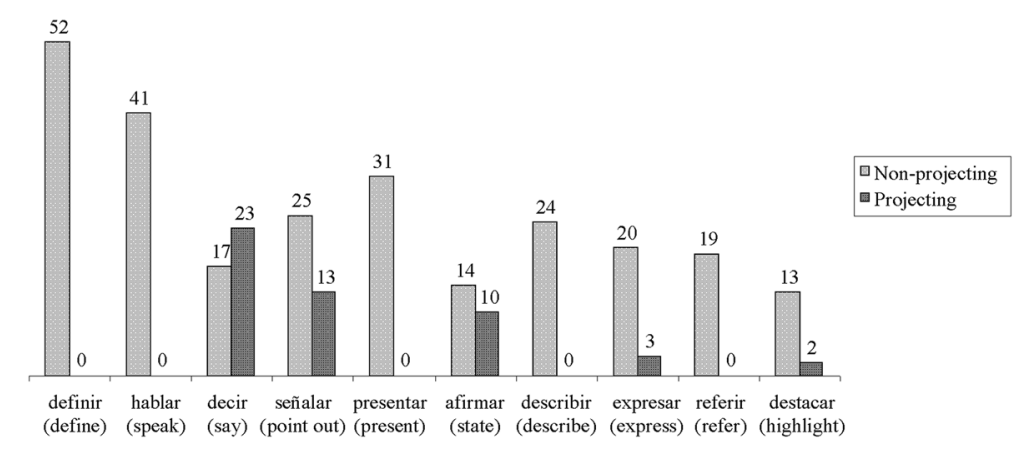

Figure 8 Projecting characteristics of the most frequent verbal processes in the expert corpus.

be realized para- or hypotactically, and, as has been observed in our corpora, it tends to be more frequent in colloquial language. On the other hand, specialized language is characterized by its relatively high degree of information condensation, frequently achieved by means of nominalizing processes. As a matter of fact, this tendency was observed in the expert corpus, since many of the verbal processes are grammaticalized as complex noun groups:

(13) La afirmación según la cual el nacionalismo y la sociedad vascos son sumamente tradicionalistas... (A, 1)

(The statement according to which basque nacionalism and society are extremely tradicionalist...)

Such complex noun groups could be unpacked as (Alguien) afirmó que el nacionalismo y la sociedad vascos son sumamente tradicionalistas ((Somebody) stated that basque nacionalism and society are extremely tradicionalist). In the student corpus, no such nominalized constructions were found, and we argue that this has to do with the colloquial language that students use.

\section{Discussion}

Our findings suggest that the presence of verbal processes in our corpora is quite substantial (23.23\% in student texts and 22.90 in expert texts), which means that these processes occupy an important place among the linguistic resources that students and experts choose to include in their writing activities. It is worth mentioning that the occurence frecuency of linguistic elements in a discourse is a good indicator of their importance in the language system. Thus, our data confirm other studies within the SAL Project which report a high percentage of verbal processes in academic and other types of discourse in Spanish (Anglada et al. in press; Herrero Rivas 2013; Zamudio Jasso 2013; etc.).

Our study makes it evident that verbal process frecuency varies from text to text depending on the genre and register, as well as on the area and topic of writing. Among the analyzed texts, reviews were the genre with the highest percentage of verbal processes. Other researchers (Anglada et al. in press; Martínez Serrano 2014) state that in newspaper notes and articles their frecuency may be even higher. All these findings corroborate the claim that verbal processes should be 
considered as one of the main process types (Matthiessen 1995) and not as a secondary type.

Our next objective was to single out the ten most frequent verbal processes and to determine their projecting characteristics (see Table 3).

It can be discerned that the number of non-projecting clauses in our corpus surpasses that of projecting ones, which clearly shows student and expert preferences in the use of verbal clause components. We can notice that Verbiage is the preferred means of transmitting the message as compared to direct or indirect locutions. Another finding is that all ten processes in our student corpus permit both projecting and nonprojecting usage, but the latter prevails.

As for the expert corpus, it is marked by an even higher percentage of non-projecting uses of the ten most frequent processes, not all of them having a "double usage". The above provides an opportunity to conclude that verbal processes with non-projecting characteristics take the lead among the different choices available for describing a communicative act.

\section{Conclusions}

In this paper we presented a quantitative and contrastive analysis of verbal processes in student texts (essays, reviews and question-answers) and expert ones (journal articles). On the one hand, the results of the quantitative analysis showed that constructions of saying and symbolizing play an important role in the language of the humanities. With verbal processes, a writer can represent both a subjective experience related to the expression of opinions and emotions and an objective one related to the construing of knowledge in the areas of Literature and Linguistics. With this important role in mind, added to the fact that verbal processes constitute a high percentage among all the processes in the corpora, Matthiessen's viewpoint according to which verbal processes are one of the four basic types seems pertinent.

On the other hand, the contrastive analysis showed that the frequency of verbal processes varies according to genre, topic, and the writers' experience. Within the student texts, the genre with the highest percentage of verbal processes was reviews. A high verbal process frequency was also found in the journal articles, in part because they deal with discourse analysis, associated with the use of a dialogic and polyphonic style, but also because of the authors' writing experience. The study also showed significant differences as to the most frequent verbal processes in the two corpora, and in their projecting characteristics. The most frequent verbal process in the student corpus was the most prototypical one (decir), whereas in the expert corpus it was definir. Besides, projection was more common amongst the student texts as they use a more colloquial and less specialized style than writers of journal articles. However, the

Table 3 Statistics of projecting and non-projecting processes

\begin{tabular}{|c|c|c|c|c|}
\hline & \multicolumn{2}{|l|}{ Student corpus } & \multicolumn{2}{|l|}{ Expert corpus } \\
\hline & \# of processes & $\%$ of processes & \# of processes & $\%$ of processes \\
\hline Non-projecting & 91 & $57.59 \%$ & 256 & $83.39 \%$ \\
\hline Projecting & 67 & $42.41 \%$ & 51 & $16.61 \%$ \\
\hline TOTAL & 158 & & 307 & \\
\hline
\end{tabular}


extended use of non-projecting processes supports the viewpoint of the linguists that include them in the group of verbal processes.

In general, the study illustrated how choice in lexicogrammatical systems such as transitivity is dependent on genre, disciplinary knowledge and writing experience. This study has shown that academic language is a fertile field of research, yet more studies need to be carried out in order to draw more convincing conclusions.

\section{Endnotes}

${ }^{a}$ The project Verbal processes in academic writing in the light of systemic functional grammar (2010-13) was carried out at the Department of Applied Linguistics (Foreign Language Centre). The participants are Natalia Ignatieva (coordinator), Victoria Zamudio, Eleonora Filice, Daniel Rodríguez and Luz Elena Herrero.

${ }^{b}$ The first theme of the SAL Project suggested by Christian Matthiessen refers to verbal processes from grammar to discourse.

"It should be noted that the notion of "genre" is not used by Halliday as a an operational systemic term (Halliday 1978; Halliday and Hasan 1989). It is introduced later in Martin's model of context (1992) as an attempt to differentiate more clearly between the context of culture and the context of situation. Martin singles out "genre" as an additional level of context and puts it above register (Martin 1993). In this way, genre is considered as determined by the sociocultural context, i.e. of a superior order, and register as determined by the situational context, i.e. of an inferior order (as shown in Figure 1). Halliday admits, however, that Martin's stratal model may be "useful" in the educational context (Martin 2013: 168-9). We also found it useful in our context taking into account the fact that the term "genre" is used by teachers as a label for text types that students produce at the university.

${ }^{\mathrm{d}}$ The selection of data was due to different factors. Thus, at the beginning the SAL Project in its Latin American version was limited to the analysis of verbal processes in research articles, but later it was decided to analyze other genres, student texts among them. Therefore, the two corpora presented in this paper were undertaken first as separate studies. Then we thought it would be useful to compare these data, as the comparative analysis coincided with the general typological goal of the SAL Project, which consists of examining verbal processes in different languages and in different areas, as well as in comparing their use in different registers and genres.

\section{Abbreviations}

ALSFAL: Latin American Association of Systemic Functional Linguistics; CLAE 2009: Corpus of Academic Language in Spanish; ISFC: International Systemic Functional Congress; UNAM: National Autonomous University of Mexico;

SFL: Systemic Functional Linguistics; SAL: Systemics Across Languages.

\section{Competing interests}

The CLAE project was possible thanks to the funding by University of California Institute for Mexico and the United States and El Consejo Nacional de Ciencia y Tecnología (CONACYT).

\section{Authors' contributions}

$\mathrm{NI}$ was the coordinator of the Mexican part of the CLAE project, and she is responsible for the collection of the curricular texts and their respective analysis. DV is responsible for the collection of the research articles and their respective analysis. Both authors are responsible for the writing of this manuscript. Both authors read and approved the final manuscript. 
Daniel Rodríguez-Vergara is a PhD student of Linguistics and a teacher of English as a Foreign Language at the Foreign Language Center of the UNAM.

Received: 11 December 2014 Accepted: 20 March 2015 Published online: 28 April 2015

References

Anglada, L, C Ávila, and Al Calvo. in press. Procesos verbales en dos géneros y dos lenguas: Tiempos verbales, componentes evaluativos y tipos de proyección.

Banks, D. to appear. On the (non) necessity of the hybrid category behavioural process. In Hybridity in systemic functional linguistics: Grammar, text and discursive context, eds. DR Miller and P Bayley. London: Equinox.

Caffarel, A. 2006. A systemic functional grammar of French: From Grammar to discourse. London: Continuum.

CLAE. 2009. National Autonomous University of Mexico and University of California Davies. http:// www.lenguajeacademico.info. Accessed 27 August 2010.

Colombi, MC. 2003. Un enfoque funcional para la enseñanza del ensayo expositivo. In Mi lengua: Spanish as a heritage language in the United States, eds. A Roca and MC Colombi, 78-95. Washington, DC: Georgetown University Press.

Eggins, S, and JR Martin. 1997. Genres and registers of discourse. In Discourse as structure and process: Discourse studies: A multidisciplinary introduction, ed. TVan Dijk, 230-56. London: Sage.

Ghio, E, and MD Fernández. 2005. Manual de lingüística sistémico funcional: El enfoque de M. A. K. Halliday y R. Hasan: Aplicaciones a la lengua española. Santa Fe, Argentina: Universidad Nacional del Litoral.

Halliday, MAK. 1968. Notes on transitivity and theme in English. Journal of Linguistics 4:179-215.

Halliday, MAK. 1978. Language as social semiotic: The social interpretation of language and meaning. London: Arnold.

Halliday, MAK 1985/1994. An introduction to functional grammar. London: Arnold.

Halliday, MAK. 1989. Spoken and written language, 2nd ed. Oxford: Oxford University Press.

Halliday, MAK, and R Hasan. 1989. Language, context and text: Aspects of language in a social-semiotic perspective. Oxford: Oxford University Press.

Halliday, MAK, and CMIM Matthiessen. 2004. An introduction to functional grammar, 3rd ed. London: Arnold.

Herrero Rivas, LE. 2013. Transitividad y procesos verbales en el lenguaje academico en español: Una perspectiva sistémico functional. Lenguas en Contexto 10:36-44.

Ignatieva, N. 2011. Verbal processes in student academic writing in Spanish from a systemic functional perspective. Lenguaje 39:447-467.

Ignatieva, N, and MC Colombi (eds.). 2014. CLAE: Corpus del Lenguaje Académico en Español de México y los Estados Unidos: Un análisis sistémico funcional. México: UNAM.

Ignatieva, N, and VE Zamudio. 2012. Perspectiva funcional de los procesos verbales en los escritos estudiantiles de literatura e historia en español. DELTA 28:561-579.

Lavid, J, J Arús, and JR Zamorano-Mansilla. 2010. Systemic functional grammar of Spanish: A contrastive study with English. London: Continuum.

Martin, JR. 1985. Factual writing: Exploring and challenging social reality. Oxford: Oxford University Press.

Martin, JR. 1992. English text: System and structure. Amsterdam: Benjamins.

Martin, JR (ed.). 2013. Interviews with MAK Halliday: Language turned back on himself. London: Bloomsbury.

Martin, JR. 1993. A contextual theory of language. In The powers of literacy: A genre approach to teaching writing, eds. B Cope and M Kalantzis, 116-136. London: Falmer Press.

Martin, JR, CMIM Matthiessen, and LC Painter. 1997. Working with functional grammar. London: Arnold. Martin, JR, and D Rose. 2003. Working with discourse: Meaning beyond the clause. London: Continuum.

Martínez Serrano, V. 2014. Un enfoque funcional en el análisis de la transitividad en notas periodísticas y reportes especializados sobre el período de post-recesión económica en México, MA Thesis. Mexico: UNAM.

Matthiessen, CMIM. 1995. Lexicogrammatical cartography: English systems. Tokyo: International Language Sciences.

Montemayor-Borsinger, A. 2009. Tema: Una perspectiva funcional de la organización del discurso. Buenos Aires: Eudeba.

Thompson, G. 1996/2004. Introducing functional grammar. London: Arnold.

Zamudio Jasso, VE. 2013. Procesos verbales y sus participantes en 9 textos de estudiantes de historia: Análisis comparativo entre géneros. Lenguas en Contexto 10:25-35. 